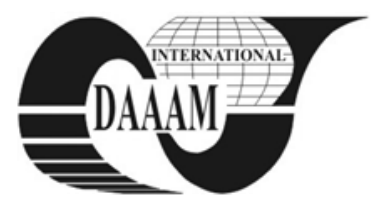

Annals of DAAAM for 2011 \& Proceedings of the 22nd International DAAAM Symposium, Volume 22, No. 1, ISSN 1726-9679 ISBN 978-3-901509-83-4, Editor B. Katalinic, Published by DAAAM International, Vienna, Austria, EU, 2011 Make Harmony between Technology and Nature, and Your Mind will Fly Free as a Bird Annals \& Proceedings of DAAAM International 2011

\title{
DIES GEOMETRY INFLUENCE IN WIRES TREATMENT IN ROPERY
}

\author{
TITTEL, V[iktor]; ZELENAY, M[iroslav] \& SOBOTA, R[obert]
}

\begin{abstract}
Contribution deals with an influence of dies geometry on processing of steel wires in a ropery. Experiments were carried out at the drawing and bunching of wires with diameter $0.30 \mathrm{~mm}$ and tensile strength approximately

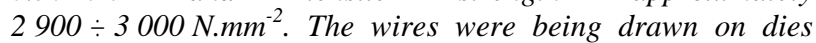
with drawing angle size $2 \alpha=11^{\circ}$ and $2 \alpha=13^{\circ}$ from two producers. The drawn wires were being bunched on double twisted machines. The count of wire fractures were mathematically and statistically evaluated. It was also monitored total quantity of material which was processed during this experiment. A positive influence of restriction of drawing die angle from $13^{\circ}$ to $11^{\circ}$ at the bunching process was found. Mainly count of wire fractures and mass of wires scrap were significant decreased at the bunching of steelcords
\end{abstract}

Key words: steelcord, reduction, geometry of die, wire, bunching process

\section{INTRODUCTION}

The die is a basic tool which is used at a drawing process of steel wire. The die is constructed so that it ensures two different operations: lubrication and plastic deformation. Besides it ensures required size accuracy, surface quality and required mechanical properties. Die geometry influence in bunching process of steelcords (SC) will be found in the contribution (Wright, 2011; Tittel \& Zelenay, 2009).

The efficiency of deformation work also depends on die geometry and mainly on drawing die angle $2 \alpha$. The biggest efficiency of deformation work at the wire drawing through a die ranges in relative narrow band of elected die angle $2 \alpha$.

The size of drawing angle also influences lubrication efficiency. The restriction of drawing angle could decrease friction factor $\mu$ from 0.05 to 0.005 . A reason is that the lubrication gains more hydrodynamic character (Enhang, 2005; Marcol, 1996).

If we consider a constant friction coefficient $\mu$ then the drawing force will be determined by the geometry and reduction. The die geometry and reduction influence following factors:

- drawing force,

- warm generated from friction and lubricant degradation, strain hardening,

risk for an occurrence of wire fracture.

And exactly the last factor led us to experiment with main target to follow up a wire processing in the rope factory which was drawn by dies with different die geometry.

\section{EXPERIMENTAL GOALS}

Before the realization of experiment it was supposed the value restriction of drawing angle $2 \alpha$ contributes to decreasing of friction factor and better conditions of lubrication at the wire drawing. At the same time it was supposed that the better conditions of lubrication contribute to lower dies wear and also better surface quality of wire, which is very important for bunching.
The change of dies geometry consisted in a change of drawing angle $2 \alpha$ from original $13^{\circ}$ to verified $11^{\circ}$. Main requirements for the SC wire are breaking force, size accuracy, very good fatigue properties and quality of surface. The very significant indicator is a count of fractures per tonnage of produced SC. The indicator talks about the quality of produced wire.

Remark: Two indicators of workability were measured in bunching process ( $1^{\text {st }}$ indicator was count of fractures per production quantity at the bunching of $\mathrm{SC}, 2^{\text {nd }}$ indicator was quantity of produced wire which was separated into scrap because of too often fractures occurrence).

\section{DISCRIBING}

Our experiment proceeded in a wet wire drawing shop or also said in a fine drawing shop and ropery at bunching of SC. $\mathrm{SC}$ wire with diameter $0.30 \mathrm{~mm}$ was being produced in the wet wire drawing shop. The type of wire was used like semiproduct for a bunching of SC construction $2 \times 0.30$.

The wire with diameter $0.30 \mathrm{~mm}$ was produced from a patented semi-product and the surface of semi-product was coated by brass. The experiment was executed at the using die series with 20 dies and drawing speed $\mathrm{v}=18 \mathrm{~m} . \mathrm{s}^{-1}$. The dies from company "A" were used in preference. The dies geometry from company "A" was standard delivered with a drawing angle $2 \alpha=13^{\circ}$ and the dies were prepared in a local die shop (A13). The dies from the company "A" were compared with dies from supplier " $B$ " and which were prepared with a drawing angle $2 \alpha=13^{\circ}$ (B13) and $2 \alpha=11^{\circ}$ (B11). The drawn wire was consequently processed in rope shop. The processing of standard wire (A13) was compared with a wire processing of $\mathrm{B} 13$ and $\mathrm{B} 11$ in the rope shop. The each wire group was processed in the rope shop as self-running i.e. segregated from other groups.

\section{RESULTS}

The following of mechanical properties were continuously carried out. The breaking force results of wire are shown in Tab. 1.

\begin{tabular}{|c|c|c|c|}
\hline \multirow{2}{*}{ Statistic date } & \multicolumn{3}{|c|}{ Breaking Force } \\
\cline { 2 - 4 } & A13 & B13 & B11 \\
\hline $\mathrm{n}[-]$ & 189 & 128 & 130 \\
\hline $\bar{x}[\mathrm{~N}]$ & 211.1 & 205.6 & 208.8 \\
\hline $\operatorname{Min}[\mathrm{N}]$ & 206.8 & 199.5 & 202.8 \\
\hline Max [N] & 216.1 & 209.8 & 218.4 \\
\hline $\mathrm{s}[\mathrm{N}]$ & 2.413 & 2.241 & 3.697 \\
\hline $\mathrm{Cpk}[-]$ & 1.26 & 3.49 & 2.88 \\
\hline & \multicolumn{3}{|c|}{ Tensile strength } \\
\hline $\bar{x}\left[\mathrm{~N} \cdot \mathrm{mm}^{-2}\right]$ & 2963.2 & 2898.7 & 2947.3 \\
\hline
\end{tabular}

Tab. 1. Breaking force, tensile strength of wire $\phi 0.30 \mathrm{~mm}$

Where: $\bar{x}$ - mean value (average), s - standard deviation, LSL - lower specification limit, USL - upper specification limit 


$$
\begin{gathered}
C p l=\frac{\bar{x}-L S L}{3 . s} \quad C p u=\frac{U S L-\bar{x}}{3 . s} \\
C p k=\min (C p u, C p l)
\end{gathered}
$$

Remark: Cpk, $\mathrm{Cpl}, \mathrm{Cpu}$ - coefficients of process capability

The all tested wires fulfilled conditions of breaking force

\begin{tabular}{|c|c|c|c|c|c|c|c|c|c|}
\hline & \multicolumn{3}{|c|}{$\mathrm{A} 13$} & \multicolumn{3}{|c|}{ B13 } & \multicolumn{3}{|c|}{ B11 } \\
\hline & $\begin{array}{l}\text { Prod. } \\
\text { [ton] }\end{array}$ & $\begin{array}{c}\text { Scrap } \\
{[\%]}\end{array}$ & $\begin{array}{c}\text { Fractures } \\
\text { [n/day] }\end{array}$ & $\begin{array}{l}\text { Prod. } \\
\text { [ton] }\end{array}$ & \begin{tabular}{|} 
Scrap \\
{$[\%]$}
\end{tabular} & $\begin{array}{c}\text { Fractures } \\
{[\mathrm{n} / \mathrm{day}]}\end{array}$ & $\begin{array}{l}\text { Prod. } \\
\text { [ton] }\end{array}$ & \begin{tabular}{|c|} 
Scrap \\
{$[\%]$}
\end{tabular} & $\begin{array}{c}\text { Fractures } \\
{[\mathrm{n} / \text { day }]}\end{array}$ \\
\hline & 362.2 & & & 186.1 & & & 113.4 & & \\
\hline vo & 8.2 & 3.61 & 7.7 & 4.2 & 4.17 & 10.8 & 255. & 0.92 & 4.70 \\
\hline
\end{tabular}
in the tolerance range from $180 \mathrm{~N}$ (LSL) up to $230 \mathrm{~N}$ (USL).

Tab. 2. Workability of wire in ropery

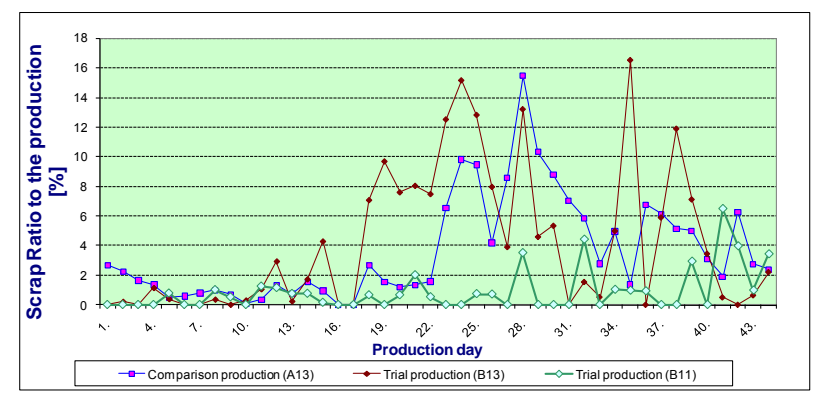

Fig. 1. Mass of scrap at the bunching process

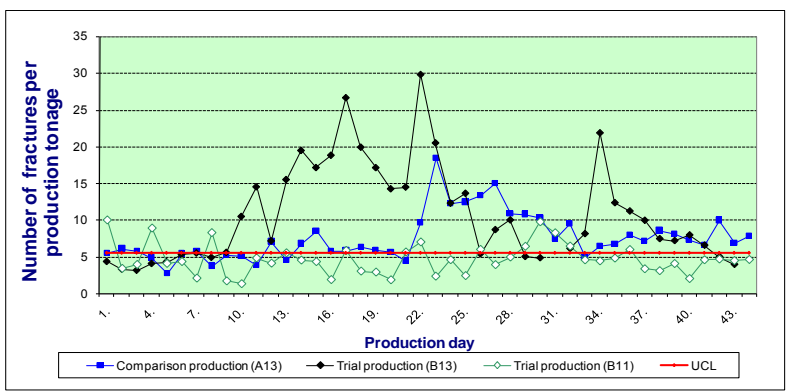

Fig. 2. Count of fractures at the bunching

\section{DISCUSSION}

As it can be seen from previous figures the quality and workability of drawn wire at bunching process expressive varied especially at the wires from groups A13 and B13.

The used dies were analyzed and it was found out that approximately $5 \%$ of all dies had marks of abnormal wear (grooves, rings and surface peeling). At the beginning it was predicted a idea that the worse conditionals of lubrication at the dies with higher value of drawing angle $2 \alpha$ (A13 and B13) can be the reason for earlier dies wear and this idea was confirmed. The consequence of dies wear was that the drawn wire had a surface with grooves which caused fractures at the bunching process. The damage of die core is demonstrated in the Fig. 3.

It was found out that the grooves on wire did not have too important influence on resultants of breaking force. The grooves had much bigger influence on the torsion loading which is characteristic for wires stranding especially on the double twisted machines. The occurrence of extreme wires was registered at the bunching on double twisted machines in the certain production phase. An explanation for the declaration is explicit. As small surface wire damage at the torsion loading leads to easy and quick material destruction. Otherwise it can be said that the surface damage supports breakage initialisation especially at the bunching where each millimetre of bunched material (wire) is verified on the torsion. It can be seen from the process graphs that the best results in the bunching process were achieved at the wire processing which was drawn with dies of B11 group. The count of fractures per tons of production was calculated only 4.70 (tolerance was defined 5.50 fractures per tons). Workability of wires from the groups A13 and B13, i.e. drawn with dies which had drawing angle $2 \alpha=13^{\circ}$, was essentially worse as wires of B11 group (see Tab. 2. and Fig. 1. and 2). Expressive scrap elimination from $3.61 \%$ at A13 against $0.92 \%$ at $\mathrm{B} 11$ was achieved by the reduction of fractures and enhancement of drawing process.

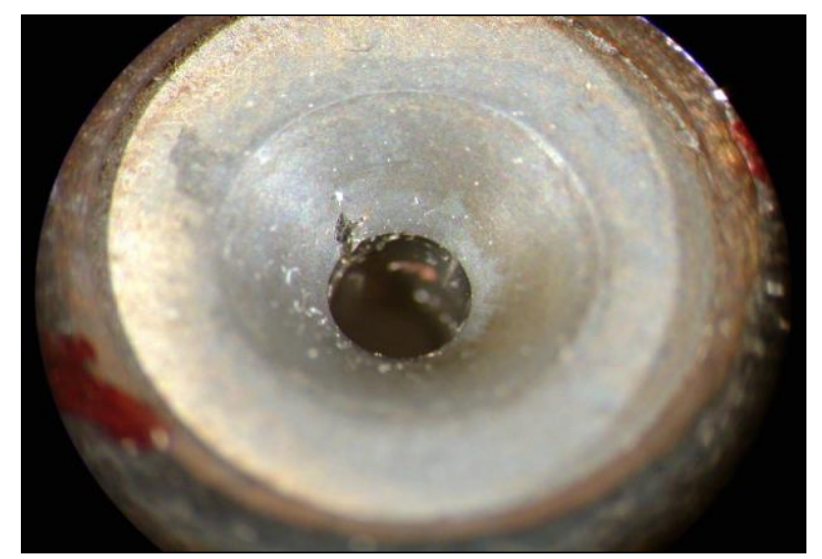

Fig. 3. Die core damage in wet wire drawing during the experiment

\section{SELF-ADDITION TO THIS PROBLEM}

The topic of geometry change influence of drawing tool (die) on the workability of drawn wire in the rope shop at the bunching process is worked out and evaluated in this contribution. The idea of better workability was predicted and confirmed by the long term experiment at the wires drawing with dies which had lower value of drawing angle (in our case $2 \alpha=11^{\circ}$ ).

\section{CONCLUSION}

Experiment has demonstrated that the dies geometry influences not only resultants of mechanical properties, dies wear, total dies consumption in the drawing process but essentially also influences following process i.e. bunching process of steel wires. It also proves our experiment which was carried out direct in production conditionals continuously with the standard production so that the other production effects were eliminated.

The experiment demonstrated a way for the next improvement of bunching process at the SC production and also the losses elimination in the production process. On the base of this experiment it could be recommended:

- die drawing angle exchange from the initial $2 \alpha=13^{\circ}$ to $2 \alpha=11^{\circ}$,

- more often dies exchange in the drawing process and more consistent dies checking.

\section{REFERENCES}

Enhang, P. (2005). Steel wire technology, Repro Örebro University, ISBN 91-631-1962-5, Örebro (Sweden)

Marcol, J. et al. (1996). Drawn steel wire $-1^{\text {st }}$ Part, ŽDB, Bohumín

Plášek, B., Tittel, V. (1987) Lime-based Lubricants improve wire drawing. In: Wireworld International, Vol. 29, No. 2, p. 33-34

Tittel, V.; Zelenay, M. (2009). A comparison of die geometry in the drawing process. In: Research papers Faculty of Materials Science and Technology Slovak University of Technology in Trnava, No. 26, AlumniPress, p. 81-86, SUT Bratislava, ISSN 1336-1589, Bratislava

Wright, R. N. (2011). Wire technology: Process Engineering and Metallurgy. Butterworth - Heinemann, ISBN 978-012-382092-1, Burlington (USA) 